\title{
LELIC - Laboratório de Estudos em Linguagem, Interação e Cognição
}

\author{
Daniel Nehme Müller ${ }^{1}$, Andréa Konzen da Silva ${ }^{23}$, Maribel Suzane Selli ${ }^{3}$, Sansão \\ Timbane $^{3}$, Otto Braitback ${ }^{4}$, Daniel Epstein ${ }^{5}$, Joelma Remião ${ }^{3}$ e Margarete Axt ${ }^{6}$ \\ Conexum Ltda. ${ }^{1}$ \\ Departamento de Informática, Universidade de Santa Cruz do Sul (UNISC) ${ }^{2}$
}

Laboratório de Estudos em Linguagem, Interação e Cognição, Universidade Federal do

Rio Grande do Sul (UFRGS) ${ }^{3}$

Programa de Pós Graduação em Informática na Educação, Universidade Federal do Rio

Grande do Sul (UFRGS) ${ }^{4}$

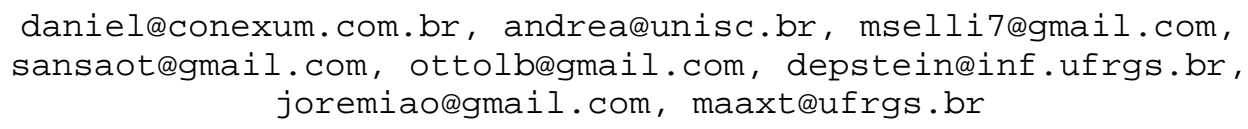

O Grupo de Pesquisa "LELIC - Laboratório de Estudos em Linguagem, Interação e Cognição: metodologias para formação em rede/EAD, sentido e autoria, criação em hipermídia" é uma equipe interdisciplinar que vem desenvolvendo objetos e ambientes virtuais de aprendizagem, bem como ações pedagógicas que considerem a interação com tecnologias digitais, enfatizando a construção do conhecimento e a produção de sentidos. Compõe o LELIC um grupo de pesquisadores da UFRGS (Universidade Federal do Rio Grande do Sul) de nível de Pós-Graduação (PPGs Educação - PPGEDU e Informática na Educação - PPGIE) e Graduação, visando o desenvolvimento de tecnologias cada vez mais integradas às demandas teórico-práticas educacionais e sociais. Investiga formação em rede (presencial/distância), efeitos da interação em espaços de linguagem $e$ do agenciamento de tecnologias em relação de coexistência, nos planos da autoria coletiva, criação estética e construção do conhecimento, sob perspectiva ética da escuta e do cuidado com os sentidos. LINHAS DE PESQUISA: 1)PROVIA - Problematizações dos Processos de Investigação do Virtual, da Criação e da Autoria. Projetos: a)Forchat e diário virtual: autorias mestiças - apoio do edital 12/2010 - SEAD/UFRGS; b)Mapeamentos cartográficos dos planos de produção analítica em pesquisa: articulações entre o comum e o diverso - apoio do edital AT-CNPq 2010; c)Deslizamentos de sentido, posições efêmeras de autoria: o lugar da multiplicidade da formação docente em rede - Bolsa $P Q / C N P q$; d) Ao provia também está vinculada uma bolsa de iniciação científica PIBIC/UFRGS. 2)CIVITAS - Cidades Virtuais com Tecnologias para Aprendizagem e Simulação. Projetos: a)Brasil-Moçambique: formação continuada em serviço e prática docente em séries iniciais do ensino fundamental - CNPq Pró-África: Edital MCT/CNPq $n^{o}$ 12/2008; b)Convênios de cooperação pesquisa-extensão entre a UFRGS e as prefeituras de: Mato Leitão/RS e Cruzeiro do Sul/RS. 3)COSMOPOLITA: Simuladores de Cidades em Rede. Projeto: Città Cosmopolita - apoio Edital MEC/CAPES e MCT/CNPq/FINEP N 28/2010 (PNPD 2010), edital MCT/CNPq $N^{o} 75 / 2010$ (RHAE Pesquisador na Empresa) $e$ Edital Universal - CNPq $N^{o}$ 14/2011. Colaboram com o LELIC a empresa CONEXUM e a Associação dos Municípios do Vale do Rio Pardo. 